Working Papers in Economics

Economic Convergence in the EU: A Complexity Approach

Gül Ertan Özgüzer and Ayla Oğuş Binatlı

Izmir University of Economics

Department of Economics

Working Paper No. 15/03

October 2015

Izmir University of Economics

Department of Economics

Sakarya Cad. No: 156

35330, Balcova Izmir

TURKEY 


\title{
Economic Convergence in the EU: A Complexity
}

\section{Approach}

\author{
Gül Ertan Özgüzer ${ }^{+}$ \\ Izmir University of Economics, Department of Economics \\ Ayla Oğuş Binatlı \\ Izmir University of Economics, Department of Economics
}

November 6, 2015

\begin{abstract}
This paper tests, in the context of the EU countries, the evidence presented by Hidalgo and Hausmann (2009) that economic complexity indicator is a good predictor of economic growth. Our results suggest that a group of countries in the EU with an economic complexity exceeding a certain threshold tends to converge to the levels of income corresponding to their measured complexity. On the other hand, current account deficits in interaction with economic complexity have important effects on growth for a second group of countries with lower levels of complexity. We also find that income convergence is faster within the first group. Therefore, we argue that convergence is much faster for countries whose economic complexity exceeds certain a threshold.
\end{abstract}

\section{JEL Classification: O11, O52, F43}

Key words: economic complexity, growth, income convergence, European Union, heterogeneity

*The authors would like to thank Alper Duman and participants of the Seventh Conference on Economic Challenges in Enlarged Europe, held on June 14-16, 2015, in Tallinn, Estonia, for their comments and discussions.

${ }^{\dagger}$ Corresponding author: gul.ertan@ieu.edu.tr 


\section{Introduction}

Economic complexity, the ability of a country to transform its economic structure towards the production and export of more sophisticated products, has emerged as a key factor in explaining economic growth and development (Hausman et al., 2007; Hidalgo and Hausman, 2009). The relatedness of products in global trade referring to product space (Hidalgo et al., 2007; Hausmann et al., 2007) portrays the productive structure of each country, and provides paths through which countries can spread to nearby products and increase their productive capacities. The higher the proximity between a pair of products, the closer the requisite capabilities to produce these two products. Therefore, a country exporting one product can easily transfer to the other product, and thereby increase its productive structure (Hidalgo et al., 2007; Hausmann and Klinger, 2007; Hidalgo and Hausmann, 2007). A variant of this idea, introduced by Hidalgo and Hausmann (2009) is the method of reflections, which evaluates sophistication of products and complexity of countries through joint and iterative calculations of ubiquity and the diversity indicators. These authors claim that the concept of economic complexity is closely related to the capabilities of a country. A country with more diverse capabilities can produce more complex products, requiring a varying set of capabilities in its production process, which can be inferred from the product's ubiquity, and from the diversity of countries that export it. Their main argument is that the growth path of an economy is determined by the overall complexity of a country's productive structure and, in turn, its ability to produce and export sophisticated products requiring diverse capabilities. The authors validate the theory by presenting cross-country evidence that economic complexity is strongly correlated with income per capita, and that deviations from this correlation are predictive of subsequent economic growth and development (Hidalgo and Hausman, 2009; Hausman et al., 2011). This cross-country regression result revives the question of whether the complexity-growth relationship is confirmed in the context of the European Union (EU), within which the newer, lower-income members tended to grow faster, implying absolute 
beta-convergence across the Union (See Figure 1). ${ }^{1}$

The trade relations within the EU are undoubtly an integral part of the Union. Moreover, the FDI received by the new entrants have served to designate them as the producers of specific goods, primarily for the European market. These dynamics are closely linked to the economic complexity of the countries. Thus, investigating the effect of economic complexity on growth in this part of the world with its particular and distictive economic and trade relations, could help shed light on the significance of economic complexity for economic growth and convergence in the EU.

Accessions of lower income countries from Central and Eastern Europe to the EU during the last decade have brought renewed interest in the issue of the narrowing of the gap between old and new members so that a number of studies have examined beta-convergence within the enlarged EU considering different sample periods and methods. $\left.\right|^{2}$ Matkowski and Prochniak (2007) confirm betaconvergence in per capita real GDP between 8 new member states and the EU-15 during the period of 1993-2004. Kocenda et al (2006) find evidence for real income per capita convergence of 10 new member countries towards EU standards between 1995 and 2005, but highlight significant growth disparities among these countries. Ingianni and Sdarek (2009) support the process of beta-convergence in real income per capita within both the group of new entrants and the whole Union over the 1995-2006 period, but argue that the convergence rate within the former group is higher. Cavenaile and Dubois (2011) provide evidence for betaconvergence of real income per capita for the EU-27 over the 1990-2007 period. However, they point to the existence of significant differences in convergence processes between new entrants and the EU-15. More recently, Dobrinsky and Havlik (2014) find uneven real economic convergence within the EU-27 over the period 2000-2011, highlighting differences in growth patterns between new

\footnotetext{
${ }^{1}$ Lower-income new members grew faster than the core members of the EU between 1995 and 2011 except the years of global crisis starting in 2008 and there were growth disparities among each other.

${ }^{2}$ Beta-convergence can be unconditional (absolute) or conditional, the latter meaning controlling for other country-specific variables than initial income per capita. Empirical applications of the hypothesis originate with Baumol(1986), Barro and Sala-i Martin (1992), and Mankiw et al (1992). We focus on papers that examine real income per capita convergence in the enlarged EU.
} 
members and the other countries. In summary, reviewed empirical literature supports beta-convergence hypothesis of the neoclassical growth theory within the EU, despite different convergence patterns of new and older members. ${ }^{3}$

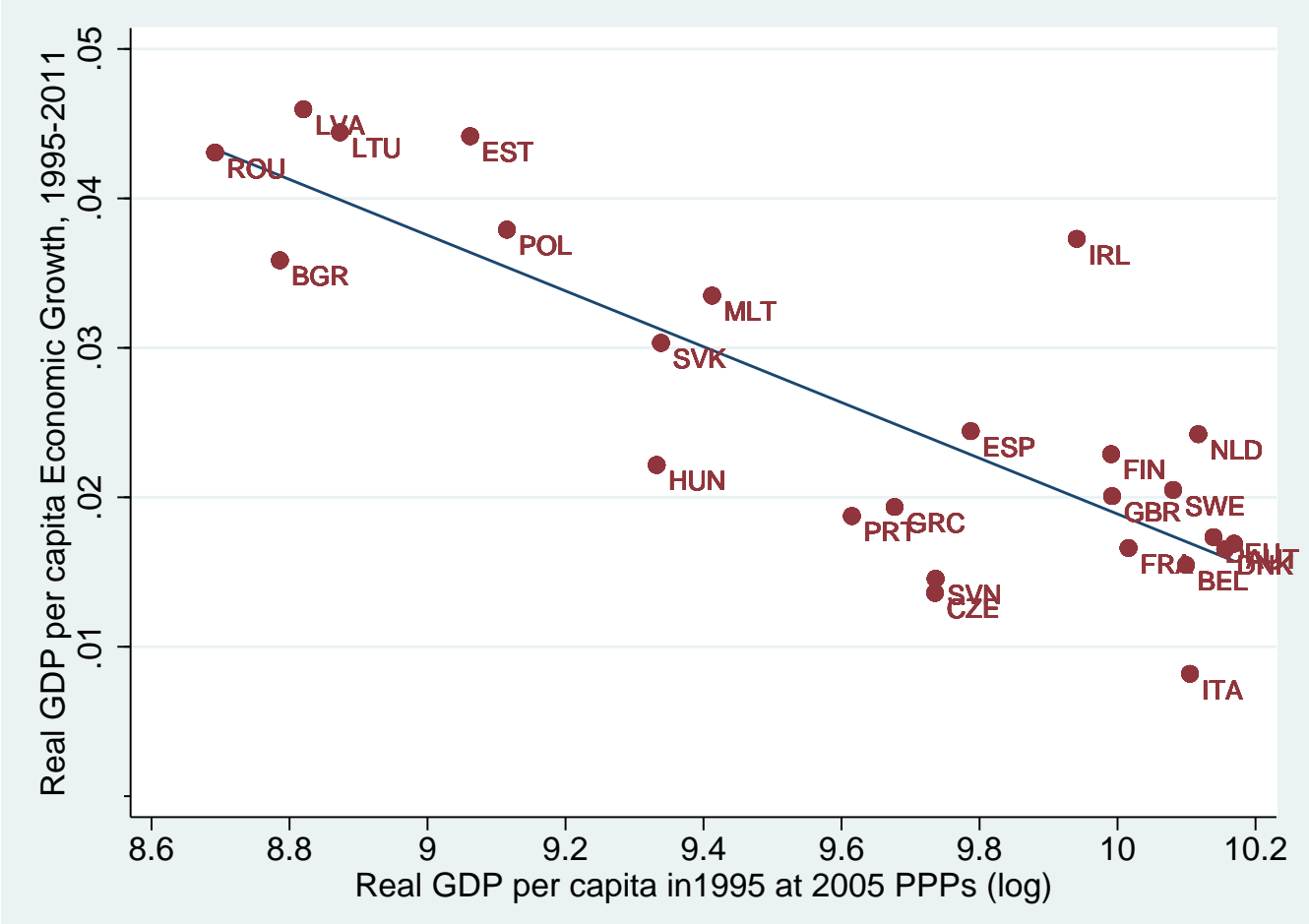

Figure 1: Beta-convergence in the EU, 1995-2011

This paper contributes to the literature relating beta-convergence within the EU and the economic complexity indicator developed by Hidalgo and Hausmann (2009). The objective is twofold. First, we check whether there has been a beta convergence within the EU in the period 1995-2010, controlling for economic complexity apart from the other traditional determinants of economic growth. After confirming the catching-up process, we furher scrutinize whether there has been a uniform convergence within different subsets of countries. Second, we take the opportunity to test, in the context of the EU countries, Hidalgo and Hausmann's (2009) finding of a positive and significant association between

\footnotetext{
${ }^{3}$ Employing an econometric analysis adapted from a neoclassical growth model augmented with endogenous technological progress which varies across countries and over time, Borsi and Metiu (2014) find no evidence of real income convergence within the EU either for the periods 1995-2010 and 1970- 2010. Yet, they identify a seperation between new EU members and the old member countries in the long run. Our paper is is mostly related with previous literature as we follow the neo-classical growth theory with exogenous technological process.
} 
economic complexity and the subsequent real GDP per capita growth.

We first compute economic complexity for 25 EU counties, and run the regression equation establishing the link between economic complexity and the GDP per capita growth ${ }^{4}$ The baseline model builds on a fixed-effect estimation employing panel data. The regression includes both country and time dummies. We also conduct robustness checks to take potential endogeneity and estimation issues into account.

Our findings support the evidence presented by Hidalgo and Hausmann (2009) for a group of EU countries exceeding a certain thereshold of economic complexity. The five new entrants from Eastern and Center Europe, which are Slovenia, Slovakia, Czeck Republic, Poland, and Hungary and EU-15 countries, excluding Greece, Spain, and Portugal, constitute a distinct group (first group) in the EU, for whom a high economic complexity index has led to a faster subsequent economic growth. The inclusion of Slovakia, Czeck Republic, Poland, and Hungary in the first group is in line with the report of IMF (2013), which posits that the integration of these four new members in a German-Central European supply chain, specifically in knowledge-intensive or high technology sectors has led them to grow faster. Similarly, Slovenia has integrated to European and global supply chains of production and trade in similar roles to those of the core EU countries (Bohle and Greskovits, 2012).

There is a negative correlation between economic complexity and future economic growth for the second group, which consists of all other EU countries. Therefore, in the European context, in order for the effect of complexity on subsequent economic growth to materialize, a country's complexity index should exceed a certain level. Moreover, the first group displays a higher convergence rate, thus implying a heterogenity across the Union. Therefore, we argue that convergence is much faster for countries whose economic complexity exceeds a certain threshold.

In order to confirm our results, we rely on the argument of Gill et al. (2012) and Stojkov and Zalduendo (2011) that capital inflows have supported growth in many emerging European countries, and therefore add current account balance

\footnotetext{
${ }^{4}$ We exclude Luxembourg, Cyprus, and Croatia from our analysis due to data limitations.
} 
to our estimation equation as a proxy for these flows. The aim here is to understand the effect of capital flows on the contribution of economic complexity to future economic growth. Our empirical results suggest that the impact of economic complexity on growth decreases with current account deficit, i.e capital inflows, across the second group of countries. This finding clearly explains why there is a negative association between economic complexity and GDP per capita growth for the second group of countries. In fact, capital inflows have triggered rapid growth in these countries without high economic complexity.

The structure of the paper is as follows. Section 2 describes the construction of economic complexity index. Section 3 explains data and methodology. Section 4 presents empirical results and robustness checks, and Section 5 concludes.

\section{Economic Complexity Index}

In this paper, we use the method of reflections developed by Hidalgo and Hausmann (2009), which evaluates sophistication of products and complexity of countries through joint and iterative calculations of ubiquity and the diversity indicators. They argue that a country possessing diverse capabilities in its production process will have a diversified export basket and a high level of economic complexity. Likewise, a product requiring diverse capabilities in its production process, is likely to be exported by fewer countries, and is expected to be more sophisticated or less ubiquitous. They use the global trade network of countries and products in their method of reflections to jointly and iteratively calculate the ubiquity and diversity indicators. The method of reflections indicators consider only those products whose revealed comparative advantage index (RCA) (Balassa, 1964), i.e. the ratio of the share of a given product in the country's export basket to the share of the product in the total world export basket, is greater than

1. RCA is computed as follows:

$$
R C A_{j k}=\frac{x_{j k} / X_{j}}{\sum_{j}\left(x_{j k} / X_{j}\right)}
$$

Ubiquity and diversity indicators are computed as follows: 


$$
\begin{aligned}
& \text { Ubiquity }_{k}=K_{k, 0}=\sum_{j} M_{j k} \\
& \text { Diversity }_{j}=K_{j, 0}=\sum_{k} M_{j k}
\end{aligned}
$$

where $j$ denotes the country, $k$ the product, and $M_{j k}$ is equal to 1 if country $j$ exports product $k$ with revealed comparative advantage and 0 otherwise. Ubiquity and diversity indicators show, respectively, the ubiquity of the product, that is, the number of countries exporting the product and the diversification of a country, namely the number of products exported by that country. Iteratevely calculating ubiquity and diversity indicators give the following weighted average equations:

$$
\begin{gathered}
K_{k, n}=\frac{1}{K_{k, 0}} \sum_{j} M_{j k} K_{j, n-1} \\
K_{j, n-1}=\frac{1}{K_{j, 0}} \sum_{k} M_{j k} K_{k, n-2}
\end{gathered}
$$

where $n$ is the number of iterations.

Equations (4) and (5) are iterated until the relative rankings of the values estimated using the $n+1$ th and $n t h$ iterations are the same. These iterations yield two vectors: the vector characterizing each country and the vector characterizing each product. In this paper, equations (4) and (5) are iterated 16 times and 17 times, respectively.

To understand how higher iterations of indicators yield more information regarding the complexity of countries and products, let us look at the additional benefit derived from moving from $K_{k, 0}$ with $K_{k, 1}$ and from $K_{j, 0}$ with $K_{j, 1}$. Note that $K_{k, 0}$ represents the number of countries exporting a product (ubiquity). However, this measure does not give any information about the complexity of the countries exporting that particular product. Plugging $K_{j, 0}$ in equation (4) yields $K_{k, 1}$, which represents the average diversification of the exporting countries. Therefore, $K_{k, 1}$ includes information regarding both the ubiquity of the product and the diversification of the countries exporting that product. $K_{j, 0}$ reflects only the number of products exported by a country (diversification), which provides 
no information regarding the complexity of the exported products. Plugging $K_{k, 0}$ into equation (5) gives $K_{j, 1}$, which denotes the average ubiquity of the products exported by that country. Additional information can be gathered about the country diversification by plugging $K_{j, 1}$ in equation (4). This leads us to $K_{k, 2}$, is the average ubquity of the products exported by countries that export product $k$. Likewise, $K_{k, 1}$ leads us to $K_{j, 2}$, which is the average diversification of countries exporting similar products to those exported by country $j$. In brief, higher order iterations extract more relevant information about the complexity of the countries as well as the sophistification of the products.

Following Hausman et al (2011) we use the following equation for economic complexity index:

$$
\text { Economic Complexity }{ }_{j}^{t}=\frac{K_{j}^{t}-\sum_{c} K_{j}^{t} / n}{\sigma_{K_{j}^{t}}}
$$

where $\sum_{c} K_{j}^{t} / n$ is the yearly average across European countries in the sample, and $\sigma_{K_{j}^{t}}$ is the yearly standard deviation. Our economic complexity index corresponds to the 16 th iteration, $K_{j}^{16}$, for 1995 , which is the first year of our period.

Hidalgo and Hausmann (2009) suggest that higher iterations of their method give information regarding the complexity of products in the export basket of countries, as well as the diversification of the countries connected to them, and thereby capture the set of capabilities available in a particular country. They empirically find that their measures of economic complexity are strongly correlated with income per capita, and that future economic growth and accordingly economic development relies heavily on the complexity of a country. They confirm that their findings are valid for the 20-year period, two 10-year periods or four 5year periods between 1985 and 2005. Hausmann et al. (2011) also find significant impact of economic complexity on the future economic growth of countries for four 10-year periods between 1978 and 2008, controlling for initial income and natural resource exports. This indicator has been widely used, for instance, by Felipe et al. (2012) to rank 5107 products and 124 countries. Using the economic complexity indicator of Hidalgo and Hausmann (2009) as a proxy for upgrading, Poncet and de Waldemar (2013) find a relationship between upgrading and economic growth within 200 Chinese cities. 


\section{Data and Methodology}

We analyze the effect of initial economic complexity on economic growth in the EU countries, controlling for initial income per capita and the other determinants of growth á la Barro (1991). We use the following beta-convergence regression specification with fixed effects

$$
\begin{aligned}
\left(\log y_{j, t+4}-\log y_{j, t}\right) / 4= & a_{0}+a_{1} \log y_{j, t}+{\text { bomplex } j, t+c_{1} \text { Inv }_{j, t}} \\
& +c_{2} \text { Open }_{j, t}+c_{3} \text { FDI }_{j, t}+c_{4} \text { Hum }_{j, t}+ \\
& +\gamma_{j}+\mu_{t}+\epsilon_{j}
\end{aligned}
$$

where $y$ denotes GDP per capita in PPP terms and $j$ is the index of countries. Data on GDP per capita are taken from the latest update of the Penn World Tables. We test the model with 4-year sub-periods starting from 1995 (1995-1998, 1999-2002, 2003-2006, 2007-2010).

Complex captures the economic complexity index explained in the previous section. We retrieve the export data to compute this index for each country in our sample from the Base pour l'Analyse du Commerce International (International Trade Database at the Product Level, (BACI), as reported by Gaulier and Zignago (2010), from CEPII. We first compute the product complexity for 5017 products covering trade at the 6-digit product level for 230 countries. 55 We then compute economic complexity for the 25 EU counties, including initial GDP per capita as a control variable. The ratio of gross capital formation to GDP (Inv) is a proxy for the rate of physical capital accumulation, and the share of labor force completed tertiary education is a proxy to control for human capital (Hum). Also included are the openness rate (imports plus exports over GDP) and FDI inflows over GDP in the country. We use average rates for investment, openness, FDI, and human capital for each 4-year sub-period. The control variables other than the economic complexity and initial GDP per capita are taken from the

\footnotetext{
${ }^{5}$ Hidalgo and Hausmann (2009) worked with the SITC rev. 4 (772 products, 129 countries), the HS at the 4-digit level (1241 products, 103 countries), and the NAICS at the 6-digit level (318 products, 150 countries). The trade data is from the UN Commodity Trade Statistics.
} 
World Development Indicators (WDI) database. Finally, the regression equations contain both country and time dummies, denoted by $\gamma_{j}$ and $\mu_{t}$ respectively.

\section{Estimation Results}

Hidalgo and Hausman (2009) find that economic complexity explains growth differentials across the world. We revisit the impact of economic complexity on growth in the context of the EU and EU expansion. In the literature, consensus is emerging about three aspects of growth within the EU. Firstly, growing number of scholars find that there is income convergence in the EU. Secondly, they agree that convergence rates differ for old and new members. Thirdly, there is a consensus on that capital flows have been an important factor for growth for new member countries. These three issues, on which there is a broad consensus, are reconsiderd from the viewpoint of economic complexity in the current study.

In Table 1 we report regression results for 25 EU members where the effect of economic complexity, capital flows and their interaction are investigated. Regression (1) is our baseline regression with complexity and other conventional variables in growth regressions. Results show no significant relationship between complexity and growth. Intial GDP per capita has a significant and negative coefficient, indicating beta-convergence across EU countries. Investment rate enters with a significant and positive sign; however, our human capital measure unexpectedly enters negatively and significantly. This counterintuitive result is specific to EU countries, possibly due to some particular country characteristics affecting the sample period. While considering the reason, it is important to note that the former communist EU members have very high rates of tertiary education, while, tertiary education has become more widespread everywhere but particularly in the more developed regions of the world over time. Therefore, this pehenomenon is seen to be particularly strong in Europe. Since our period coincides with a great European recession, we may be seeing rising rates of tertiary education, coupled with low rates of growth. Openness rate and FDI enter positively as expected, but with insignificant sign.

If economic complexity cannot explain economic growth within the Union, the high growth performances of countries such as Latvia and Estonia must 
Table 1: Fixed-effects Regression Results for Economic complexity and Growth (EU Total)

\begin{tabular}{|c|c|c|c|}
\hline & \multicolumn{3}{|c|}{ GDP per capita growth (1995-2010) (4-year sub-periods) } \\
\hline & \multicolumn{3}{|c|}{ Benchmark } \\
\hline & (1) & (2) & (3) \\
\hline \multirow[t]{2}{*}{ Complexity } & -0.003 & -0.003 & 0.008 \\
\hline & $(0.01)$ & $(0.01)$ & $(0.01)$ \\
\hline \multirow[t]{2}{*}{ Initial GDP per capita } & $-0.110^{* * *}$ & $-0.110^{* * *}$ & $-0.104^{* * *}$ \\
\hline & (0.02) & (0.02) & (0.02) \\
\hline \multirow[t]{2}{*}{ Investment } & $0.267^{* * *}$ & $0.267^{* *}$ & $0.212^{*}$ \\
\hline & $(0.09)$ & $(0.11)$ & $(0.11)$ \\
\hline \multirow[t]{2}{*}{ Openness } & 0.010 & 0.010 & 0.004 \\
\hline & $(0.02)$ & $(0.02)$ & $(0.02)$ \\
\hline \multirow[t]{2}{*}{ FDI } & 0.0001 & 0.0001 & 0.0001 \\
\hline & $(0.0006)$ & $(0.0006)$ & $(0.0006)$ \\
\hline \multirow[t]{2}{*}{ Human Capital } & $-0.162^{* * *}$ & $-0.162^{* * *}$ & $-0.148^{* * *}$ \\
\hline & $(0.06)$ & $(0.06)$ & $(0.06)$ \\
\hline \multirow[t]{2}{*}{$\mathrm{CAB}$} & & -0.004 & 0.014 \\
\hline & & $(0.10)$ & $(0.10)$ \\
\hline \multirow[t]{2}{*}{$\mathrm{CAB}^{*}$ Complexity } & & & 0.104 \\
\hline & & & $(0.06)$ \\
\hline Observations & 98 & 98 & 98 \\
\hline Groups & 25 & 25 & 25 \\
\hline R-squared & 0.19 & 0.19 & 0.21 \\
\hline
\end{tabular}

Notes: ${ }^{*}{ }^{* *}$ and ${ }^{* *}$ indicate statistical significance at $10 \%, 5 \%$ and $1 \%$ respectively. Standard errors are in parenthesis. Year effects are included. 
be due to different factors. Gill et al. (2012) claim that capital inflows to the emerging countries of Europe, different from those to the other parts in the world, have helped poorer countries grow faster, enabling convergence across Europe. Moreover, Stojkov and Zalduendo (2011) show that foreign savings support growth in many emerging European countries. Figure 2 plots current account balance of the countries of the EU against their real GDP per capita growth in the period 1995-2010. A positive association between current account deficit and income growth is observed for a group of countries including Latvia, Romenia, and Estonia, which might explain fast growth in the absense of high economic complexity. Therefore, in order to see the effect of capital inflows on the contribution of economic complexity to future economic growth, we add an interaction term to our regression equation. We use current account balance to capture capital flows so that our interaction term denotes the interaction between economic complexity and current account balance. In regressions (2) and (3) current account balance is added and an interaction term between current account balance and complexity, respectively, to our baseline regression.

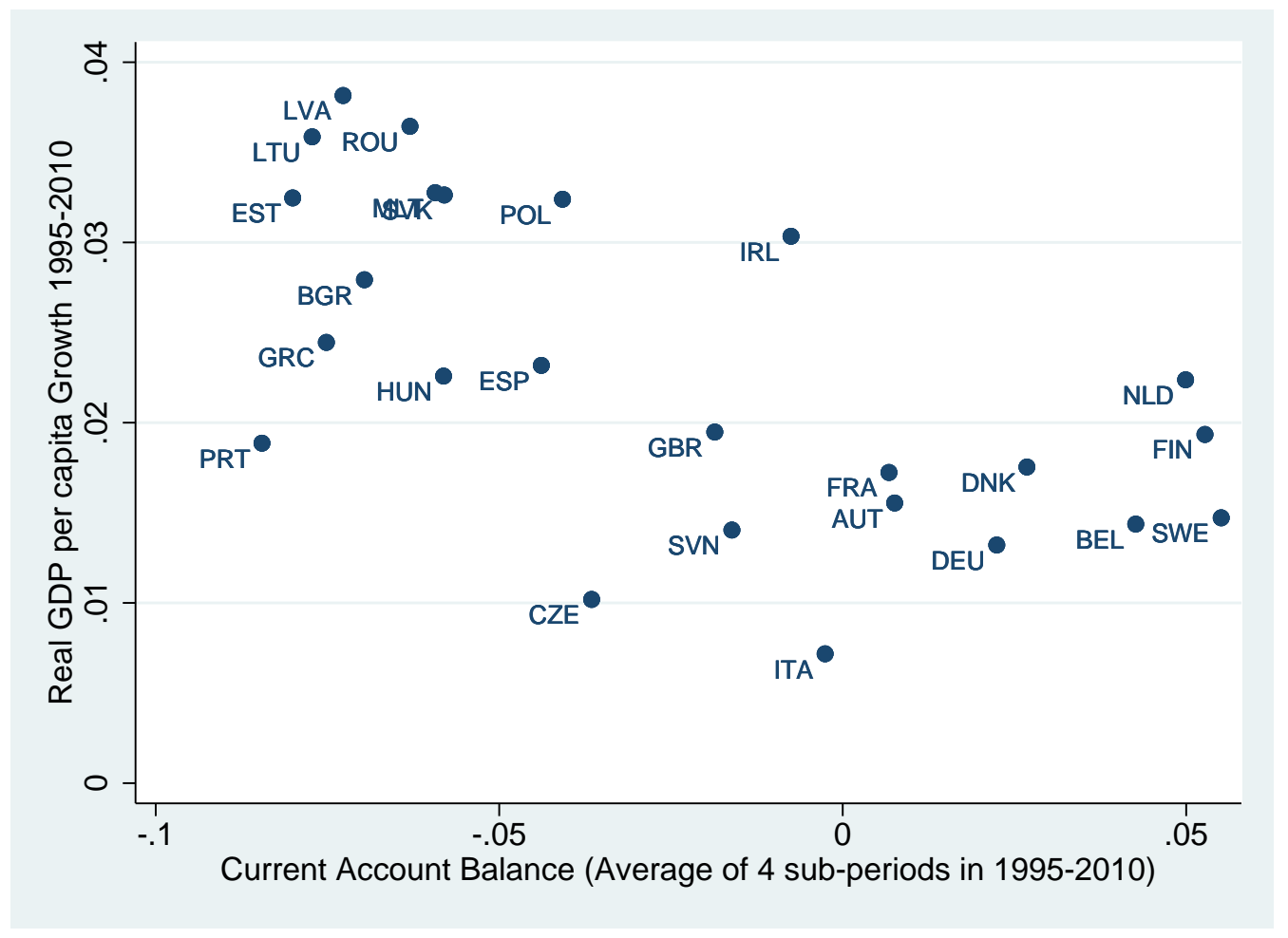

Figure 2: Economic Growth and Current Account Balance

In regression (2) we see that when we add the current account balance as 
our measure for capital flows in our growth regression, nothing is affected. The coefficient of this variable is insignificant and its inclusion in the regression has not changed any of the significant or insignificant coefficients. When we add the interaction term in regression (3), complexity, current account balance and the interaction terms remain insignificant but now we observe some changes in the other coefficients. The changes are statistically significant but not large. However, the fact that the interaction term resulted in this change is an indication that there is something there but not strong enough to be identified in a statistically significant way in this sample. The probability value of the interaction term is slightly above 10 percent.

Our results suggest that initial complexity cannot explain growth differentials in the EU where the variation is much smaller compared to a larger set of developed and underdeveloped countries. Although variations in GDP per capita and in economic complexity are not very high across EU countries compared to those within the the world, levels of GDP per capita and economic complexity are far from uniform across the Union. In this context, it would be interesting to investigate whether there exists a group of countries in the EU where economic complexity is associated with income growth, boosting beta-convergence within this group. Therefore, we compute yearly average complexity measure for each country. We categorize countries into two groups based on the complexity index. The first group includes Austria, Belgium, Czech Republic, Germany, Denmark, United Kingdom, Denmark, Finland, France, Italy, Slovenia, Netherlands, Slovak Republic, Ireland, Netherlands, Poland, Hungary and Sweden. These countries have an average complexity index higher than -0.22 . The second group includes countries with an average complexity index smaller than -0.68 , namely Bulgaria, Estonia, Spain, Lithuania, Latvia, Romenia, Portugal, Malta, and Greece ${ }^{6}$ Figure 3 plots average growth against average economic complexity for the period of 1995-2010. The figure shows that, among all adjacent countries in the EU, the largest gap between two adjacent countries is between

\footnotetext{
${ }^{6}$ We opt to divide contries into two groups based on the complexity threshold of -0.25 Separating the two groups at the 0 threshold puts Hungary and Poland in group 2. Our main findings are robust to this particular choice of threshold. The results for this alternative grouping are provided available from the authors upon request.
} 
Poland and Malta. Furthermore, most countries in either group exhibit increasing economic complexity over the sample period. Poland and Hungary reach positive levels of economic complexity towards the end of the sample period, which are reached by no other countries. Hence, if we had set the final (not average) complexity threshold at zero, we would end up with the same groups of countries. We therefore argue that several measures confirm that Poland and Hungary belong in the first group. Moreover, our results are robust regardless of which group Poland and Hungary are included in.

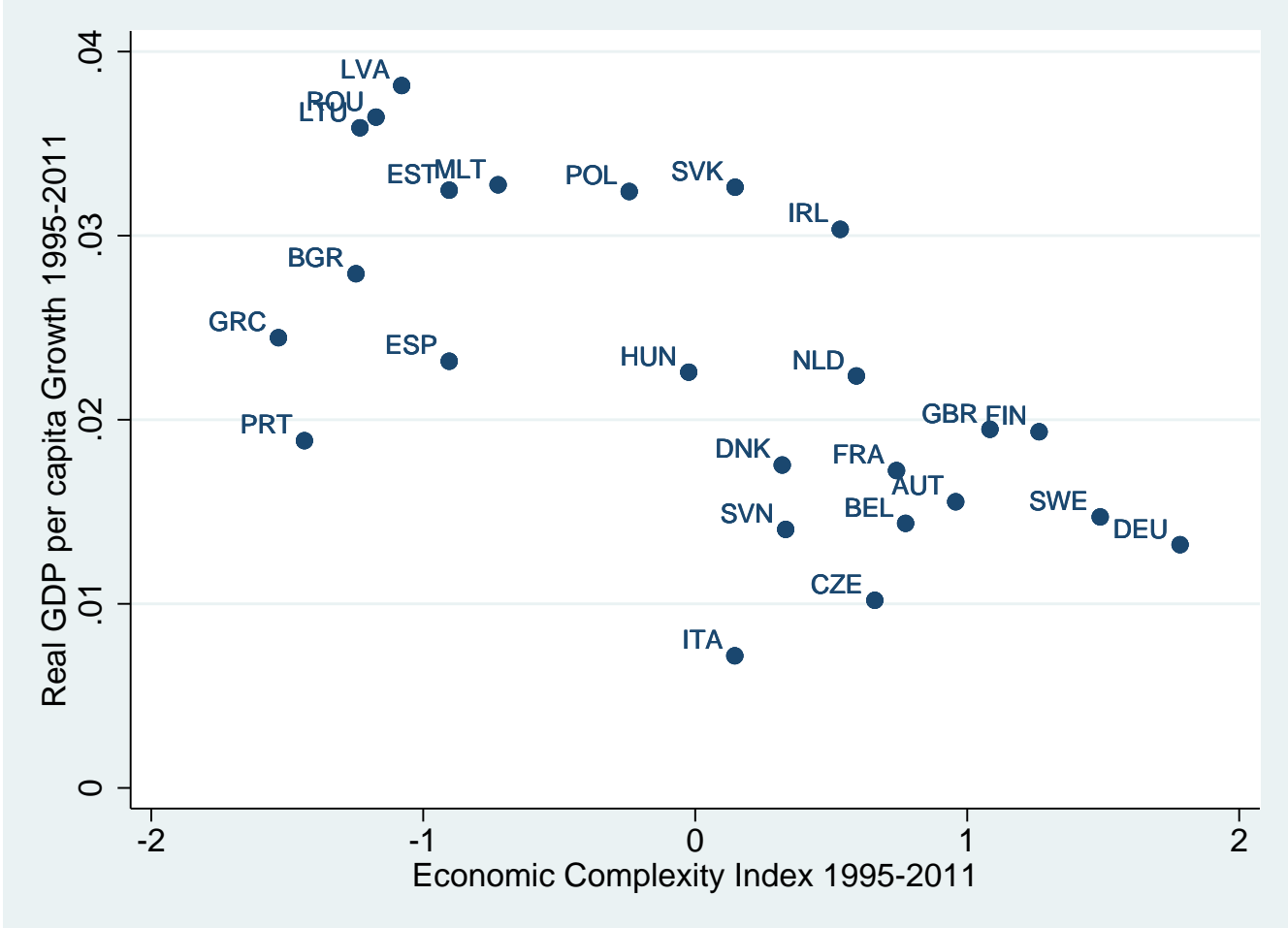

Figure 3: Average Growth and Average Complexity

In Table 2 we present the regression results for the two different groups of countries. Our regression results show that economic complexity index is strongly associated with economic growth for the first group of countries. Moreover, significant and negative coefficient of initial GDP per capita indicates a process of beta convergence across this group of countries. Therefore, our results support the findings of Hidalgo and Hausman (2009) that a group of countries in the EU with higher economic complexity tend to converge to the levels of income corresponding to their measured complexity. Excluding Hungary and Poland from the first group produces no change in results (See Appendix). 
Table 2: Fixed-effects Regression Results for Economic Complexity and Growth (Group $1 \& 2)$

\begin{tabular}{|c|c|c|c|c|c|c|}
\hline & \multicolumn{6}{|c|}{ GDP per capita growth (1995-2010) (4-year sub-periods) } \\
\hline & \multicolumn{3}{|c|}{ Group 1} & \multicolumn{3}{|c|}{ Group 2} \\
\hline & $(1)$ & $(2)$ & (3) & $(4)$ & $(5)$ & $(6)$ \\
\hline \multirow[t]{2}{*}{ Complexity } & $0.043^{* * *}$ & $0.043^{* * *}$ & $0.043^{* * *}$ & $-0.042^{* *}$ & $-0.050^{* *}$ & $-0.168^{* * *}$ \\
\hline & $(0.01)$ & $(0.01)$ & $(0.01)$ & $(0.02)$ & $(0.02)$ & $(0.03)$ \\
\hline \multirow[t]{2}{*}{ Initial GDP per capita } & $-0.144^{* * *}$ & $-0.144^{* * *}$ & $-0.144^{* * *}$ & $-0.078^{* * *}$ & $-0.083^{* * *}$ & $-0.058^{* * *}$ \\
\hline & $(0.02)$ & $(0.02)$ & $(0.02)$ & $(0.02)$ & $(0.02)$ & $(0.02)$ \\
\hline \multirow[t]{2}{*}{ Investment } & -0.041 & -0.042 & -0.023 & 0.22 & $0.32^{*}$ & 0.037 \\
\hline & $(0.12)$ & $(0.12)$ & $(0.13)$ & $(0.15)$ & $(0.18)$ & $(0.16)$ \\
\hline \multirow[t]{2}{*}{ Openness } & -0.036 & -0.036 & -0.033 & 0.048 & 0.057 & 0.058 \\
\hline & $(0.02)$ & $(0.02)$ & $(0.02)$ & $(0.04)$ & $(0.05)$ & $(0.03)$ \\
\hline \multirow[t]{2}{*}{ FDI } & -0.0006 & -0.0006 & -0.0007 & 0.0019 & 0.0026 & 0.0014 \\
\hline & $(0.0005)$ & $(0.0005)$ & $(0.0005)$ & $(0.0015)$ & $(0.0016)$ & $(0.0013)$ \\
\hline \multirow[t]{2}{*}{ Human Capital } & -0.083 & -0.084 & -0.089 & -0.085 & -0.046 & -0.033 \\
\hline & $(0.06)$ & $(0.06)$ & $(0.06)$ & $(0.11)$ & $(0.11)$ & $(0.09)$ \\
\hline \multirow[t]{2}{*}{ CAB } & & -0.015 & 0.064 & & 0.205 & $-1.647^{* * *}$ \\
\hline & & $(0.09)$ & $(0.15)$ & & $(0.20)$ & $(0.50)$ \\
\hline \multirow[t]{2}{*}{$\mathrm{CAB}^{*}$ Complexity } & & & -0.085 & & & $-1.418^{* * *}$ \\
\hline & & & $(0.12)$ & & & $(0.37)$ \\
\hline Observations & 63 & 63 & 63 & 35 & 35 & 35 \\
\hline Countries & 16 & 16 & 16 & 9 & 9 & 9 \\
\hline R-squared & 0.15 & 0.15 & 0.15 & 0.19 & 0.20 & 0.23 \\
\hline
\end{tabular}

Notes: $*, * *$ and $* * *$ indicate statistical significance at $10 \%, 5 \%$ and $1 \%$ respectively. Standard errors are in parenthesis. Year effects are included only for group 1. 
For the second group, economic complexity has a significant but negative effect. Countries with lower levels of economic complexity have higher growth. This is undoubtedly possible only due to the trade patterns within the EU. Having the advantage of access either to the EU market or to the other markets thanks to EU trade agreements, the new member countries have taken on the role of producers of goods which do not require high economic complexity. Note that within this group all countries have a negative economic complexity index.

We find no effect of the current account balance nor its interaction with complexity on growth for group 1 countries. In contrast, for the second group with low levels of economic complexity, we find significant importance of both capital flows and its interaction with complexity. The coefficient of current account balance is negative and significant, indicating that higher deficits lead to high growth. However, this effect is stronger for countries with higher complexity. Our empirical results suggest that the impact of economic complexity on growth increases with current account surplus, consistent with our previous result.

By dividing the countries based on the complexity threshold we are able to uncover the effect of complexity on growth, but the investment and human capital variables lose signficance. We observe different rates of convergence for the two groups of countries. Speed of convergence for the first group is double that of the second; therefore we argue that cathing-up is much faster for countries whose their economic complexity reaches a certain threshold.

In tables 3 and 4 we report the first difference and GMM estimates to check for the robustness of our results. Fixed-effects performs better when the errors are serially correlated. Both first-differences and fixed-effects are biased when there is endogeneity, hence comparing the estimates from fixed-effects and firstdifferences can help detect endogeneity. The estimated coefficients of statistically significant variables are similar for group 2 countries. The complexity variable is found to be negative and significant at the $10 \%$ level of significance for the whole sample, but insignificant for group 1 countries. Both of these results are consistent with previous findings.

Due to concerns over the endogeneity of complexity with variables like investment and openness, we also investigate the use of first difference and sys- 
tematic generalized method of moments (GMM) estimators á la Arellano and Bond (1991), Arellano and Bover (1995), and Blundell and Bond (1998). The sample of group 2 countries is too small for GMM estimation to be viable, so we report these results only for EU total and group 1 countries. Moreover, the similarity of first-difference and fixed-effects estimators for group 2 suggest the validity of the strict exogeneity assumption. 
Table 3: First Difference Regression Results for Economic Complexity and Growth

\begin{tabular}{|c|c|c|c|c|c|c|c|c|c|}
\hline & \multicolumn{9}{|c|}{ GDP per capita growth (1995-2010) (4-year sub-periods) } \\
\hline & \multicolumn{3}{|c|}{ All Countries } & \multicolumn{3}{|c|}{ Group 1} & \multicolumn{3}{|c|}{ Group 2} \\
\hline & (1) & $(2)$ & (3) & (4) & $(5)$ & $(6)$ & $(7)$ & (8) & (9) \\
\hline \multirow[t]{2}{*}{ Complexity } & $-0.021^{*}$ & $-0.022^{*}$ & -0.016 & 0.231 & 0.218 & 0.024 & $-0.054^{* * *}$ & $-0.058^{* *}$ & $-0.185^{* * *}$ \\
\hline & $(0.01)$ & $(0.01)$ & $(0.01)$ & $(0.02)$ & $(0.02)$ & $(0.02)$ & $(0.02)$ & $(0.02)$ & $(0.03)$ \\
\hline \multirow[t]{2}{*}{ Initial GDP per capita } & $-0.084^{* * *}$ & $-0.084^{* * *}$ & $-0.085^{* * *}$ & $-0.089^{* * *}$ & $-0.088^{* * *}$ & $-0.090^{* * *}$ & $-0.093^{* * *}$ & $-0.097^{* * *}$ & $-0.059^{* * *}$ \\
\hline & $(0.02)$ & $(0.02)$ & $(0.02)$ & $(0.02)$ & $(0.02)$ & $(0.02)$ & $(0.03)$ & $(0.03)$ & $(0.02)$ \\
\hline \multirow[t]{2}{*}{ Investment } & $0.283^{* * *}$ & $0.297^{* *}$ & $0.264^{* *}$ & 0.165 & 0.196 & 0.156 & $0.270^{*}$ & 0.354 & 0.004 \\
\hline & $(0.09)$ & $(0.12)$ & $(0.13)$ & $(0.15)$ & $(0.16)$ & $(0.16)$ & $(0.15)$ & $(0.22)$ & $(0.17)$ \\
\hline \multirow[t]{2}{*}{ Openness } & 0.039 & 0.039 & 0.036 & 0.031 & 0.031 & 0.029 & 0.037 & 0.039 & 0.081 \\
\hline & $(0.03)$ & $(0.03)$ & $(0.03)$ & $(0.03)$ & $(0.03)$ & $(0.03)$ & $(0.04)$ & $(0.05)$ & $(0.03)$ \\
\hline \multirow[t]{2}{*}{ FDI } & 0.0003 & 0.0003 & 0.0003 & 0.0000 & 0.0001 & 0.0001 & 0.0012 & 0.0016 & 0.0005 \\
\hline & $(0.0005)$ & $(0.0006)$ & $(0.0005)$ & $(0.0005)$ & $(0.0005)$ & $(0.0005)$ & $(0.0016)$ & $(0.0018)$ & $(0.0013)$ \\
\hline \multirow[t]{2}{*}{ Human Capital } & $-0.118^{*}$ & $-0.117^{*}$ & $-0.117^{*}$ & $-0.121^{*}$ & $-0.124^{*}$ & $-0.117^{*}$ & -0.060 & -0.044 & -0.115 \\
\hline & $(0.06)$ & $(0.06)$ & $(0.06)$ & $(0.07)$ & $(0.07)$ & $(0.07)$ & $(0.13)$ & $(0.14)$ & $(0.10)$ \\
\hline \multirow[t]{2}{*}{$\mathrm{CAB}$} & & 0.021 & 0.046 & & 0.066 & -0.107 & & 0.12 & $-2.075^{* * *}$ \\
\hline & & $(0.12)$ & $(0.12)$ & & $(0.14)$ & $(0.22)$ & & $(0.23)$ & $(0.50)$ \\
\hline \multirow[t]{2}{*}{$\mathrm{CAB}^{*}$ Complexity } & & & 0.091 & & & 0.202 & & & $-1.667^{* * *}$ \\
\hline & & & $(0.08)$ & & & $(0.19)$ & & & $(0.036)$ \\
\hline Observations & 73 & 73 & 73 & 47 & 47 & 47 & 26 & 26 & 26 \\
\hline Countries & 25 & 25 & 25 & 16 & 16 & 16 & 9 & 9 & 9 \\
\hline R-squared & 0.43 & 0.43 & 0.44 & 0.46 & 0.46 & 0.48 & 0.57 & 0.57 & 0.81 \\
\hline
\end{tabular}

Notes: ${ }^{*}{ }^{* *}$ and ${ }^{* *}$ indicate statistical significance at $10 \%, 5 \%$ and $1 \%$ respectively. Standard errors are in parenthesis. 
Table 4: GMM Regression Results for Economic Complexity and Growth

\begin{tabular}{|c|c|c|c|c|c|c|c|c|c|c|c|c|}
\hline \multicolumn{13}{|c|}{ GDP per capita growth (1995-2010) (4-year sub-periods) } \\
\hline & \multicolumn{6}{|c|}{ Difference GMM } & \multicolumn{6}{|c|}{ System GMM } \\
\hline & \multicolumn{3}{|c|}{ All Countries } & \multicolumn{3}{|c|}{ Group 1} & \multicolumn{3}{|c|}{ All Countries } & \multicolumn{3}{|c|}{ Group 1} \\
\hline & $(1)$ & $(2)$ & (3) & $(4)$ & $(5)$ & $(6)$ & $(7)$ & $(8)$ & $(9)$ & $(10)$ & $(11)$ & $(12)$ \\
\hline \multirow[t]{2}{*}{ Complexity } & -0.005 & -0.008 & -0.001 & $0.029^{* * *}$ & $0.023^{* *}$ & $0.022^{* *}$ & -0.011 & -0.010 & -0.005 & $0.022^{*}$ & 0.016 & 0.018 \\
\hline & $(0.01)$ & $(0.01)$ & $(0.01)$ & $(0.01)$ & $(0.01)$ & $(0.01)$ & $(0.01)$ & $(0.03)$ & $(0.03)$ & $(0.01)$ & $(0.02)$ & $(0.02)$ \\
\hline \multirow[t]{2}{*}{ Initial GDP per capita } & $-0.145^{* * *}$ & $-0.145^{* * *}$ & $-0.142^{* * *}$ & $-0.170^{* * *}$ & $-0.170^{* * *}$ & $-0.172^{* * *}$ & -0.032 & -0.032 & $-0.052^{*}$ & $-0.069^{* * *}$ & $-0.063^{* *}$ & $-0.060^{*}$ \\
\hline & $(0.03)$ & $(0.03)$ & $(0.03)$ & $(0.04)$ & $(0.03)$ & $(0.04)$ & $(0.01)$ & $(0.03)$ & $(0.03)$ & $(0.02)$ & $(0.03)$ & $(0.03)$ \\
\hline \multirow[t]{2}{*}{ Investment } & $0.230^{* * *}$ & $0.264^{* *}$ & $0.234^{* *}$ & 0.146 & 0.213 & 0.214 & 0.008 & -0.017 & 0.008 & 0.018 & 0.094 & 0.112 \\
\hline & $(0.08)$ & $(0.11)$ & $(0.11)$ & $(0.12)$ & $(0.16)$ & $(0.14)$ & $(0.10)$ & $(0.15)$ & $(0.15)$ & $(0.09)$ & $(0.12)$ & $(0.13)$ \\
\hline \multirow[t]{2}{*}{ Openness } & 0.019 & 0.020 & 0.020 & -0.026 & -0.020 & -0.018 & 0.026 & 0.025 & 0.021 & -0.011 & -0.002 & -0.002 \\
\hline & $(0.02)$ & $(0.02)$ & $(0.02)$ & $(0.02)$ & $(0.02)$ & $(0.02)$ & $(0.02)$ & $(0.03)$ & $(0.03)$ & $(0.02)$ & $(0.12)$ & $(0.03)$ \\
\hline \multirow[t]{2}{*}{ FDI } & -0.0001 & 0.0000 & 0.0001 & -0.0004 & -0.0002 & -0.0002 & -0.0003 & -0.0004 & -0.0002 & -0.0006 & -0.0005 & -0.0005 \\
\hline & $(0.0003)$ & $(0.0003)$ & $(0.0003)$ & $(0.0003)$ & $(0.0003)$ & $(0.0003)$ & $(0.0003)$ & $(0.0005)$ & $(0.0005)$ & $(0.0004)$ & $(0.0005)$ & $(0.0005)$ \\
\hline \multirow[t]{2}{*}{ Human Capital } & 0.003 & 0.0002 & 0.006 & 0.027 & 0.066 & 0.061 & -0.047 & -0.048 & -0.115 & -0.049 & 0.024 & 0.027 \\
\hline & $(0.08)$ & $(0.08)$ & $(0.09)$ & $(0.09)$ & $(0.08)$ & $(0.08)$ & $(0.05)$ & $(0.09)$ & $(0.10)$ & $(0.10)$ & $(0.11)$ & $(0.11)$ \\
\hline \multirow[t]{2}{*}{$\mathrm{CAB}$} & & 0.52 & 0.070 & & 0.114 & 0.153 & & -0.031 & 0.029 & & 0.066 & -0.0002 \\
\hline & & $(0.08)$ & $(0.08)$ & & $(0.10)$ & $(0.25)$ & & $(0.18)$ & $(0.14)$ & & $(0.15)$ & $(0.28)$ \\
\hline \multirow[t]{2}{*}{ CAB*Complexity } & & & $0.090^{* * *}$ & & & -0.043 & & & $0.142^{* *}$ & & & 0.091 \\
\hline & & & $(0.03)$ & & & $(0.09)$ & & & $(0.07)$ & & & $(0.14)$ \\
\hline Observations & 50 & 50 & 50 & 32 & 32 & 32 & 75 & 75 & 75 & 48 & 48 & 48 \\
\hline Countries & 25 & 25 & 25 & 16 & 16 & 16 & 25 & 25 & 25 & 16 & 16 & 16 \\
\hline Instruments & 12 & 13 & 14 & 12 & 13 & 14 & 14 & 15 & 16 & 14 & 15 & 16 \\
\hline Sargan Test & 0.21 & 0.22 & 0.48 & 0.06 & 0.011 & 0.0006 & 8.32 & 8.05 & 9.69 & 2.86 & 3.38 & 3.24 \\
\hline p-value & 0.90 & 0.89 & 0.79 & 0.97 & 0.99 & 0.99 & 0.08 & 0.09 & 0.05 & 0.58 & 0.50 & 0.52 \\
\hline $\operatorname{AR}(1)$ & 0.27 & 0.41 & 0.33 & 0.45 & 0.42 & 0.47 & -0.21 & -0.14 & -0.30 & 0.65 & 0.69 & 0.66 \\
\hline
\end{tabular}


In Table 4, we report two-step coefficient estimates with robust standard errors. We also report the Sargan test from two-step estimation without robust standard errors and AR(1) tests from the two-step robust estimation. The difference GMM is valid under the null hypothesis of no autocorrelation. This hytpothesis needs to be tested for second order serial correlation, which was impossible with so few time periods. AR(1) test results show no first order serial correlation. However, note that this finding alone is not sufficient to conclude that this method of estimation is valid for this model and this sample. Similarly, we report the Sargan test, inspite of selecting robust standard errors. The Sargan test is only valid under the null hypothesis of homoskedatic errors and it is found to overreject in the presence of heteroskedasticty in one-step estimation and underreject in two-step estimation (Arellano and Bond 1991). Finally, Roodman(2006) warns against using excessive number of instruments, and presents the sensitivity of the bias to the number of instruments. Even though the number of cross-sections is suggested as the upper limit for the number of instruments, he recommends using significantly fewer. The number of instruments for the regressions estimated for the whole sample is reasonable given its size. The number of instruments for group 1 countries is close or equal to the number of countries, hence it is borderline regarding this requirement. The shortcomings to the regressions in Table 4 notwithstanding, we find complexity to increase growth for group 1 countries, confirming our previous results. We also find that the interaction of the current account balance with complexity is positively associated with growth for both group 1 countries and the whole sample, although the size of the effect is much smaller than the effect of the interaction variable for group 2 countries.

Finally, considering the possible effects on results of the global financial crisis of 2008, we run our regressions omitting the last sub-period, which starts in 2008. Our results are not affected. These results are not reported but are available from the authors upon request.

All in all, our paper argues that there are two groups of countries in the EU: the first group consists of countries with higher economic complexity index tending to converge to the levels of income corresponding to their measured 
complexity as evidenced by Hidalgo and Hausman (2009); the second group mostly consists of countries with lower economic complexity and higher GDP per capita growth, for this group, lower economic complexity is associated with higher growth. We also provide evidence for income convergence within the EU, but at differing rates for the two groups of member countries. We also show that capital flows in interaction with economic complexity are important for growth for a group of countries in the EU. Rather than subscribing to the traditional division among EU members as old and new, we offer an alternative based on economic complexity.

\section{Conclusion}

Our results indicate a strong association between economic complexity and growth over the 1995-2010 period in a group of EU countries with higher economic complexity, supporting the evidence presented by Hidalgo and Hausmann (2009). Therefore, countries with an inital complexity index excceding a certain threshold consequently grow faster. Convergence is twice as fast within this high complexity group. Thus, we argue that convergence is much faster across countries whose economic complexity exceeds a certain threshold.

In contrast, there is a negative correlation between economic complexity and future economic growth for the second group of countries where economic complexity is lower. We also find that the impact of economic complexity on growth decreases with current account deficit across the second group, which gives a strong indication of the reason why this group of countries could achieve high growth rates without high levels of economic complexity.

Subsequent research should focus on the explicit mechanisms by which some European countries develop capabilities to produce more complex products that are conducive for future growth.

\section{References}

Arellano, M., and S. Bond. 1991. "Some Tests of Specification for Panel Data:

Monte Carlo Evidence and an Application to Employment Equations." The 
Review of Economic Studies 58: 277 - 97.

Arellano, M., and O. Bover. 1995. "Another Look at the Instrumental Variable Estimation of Error-components Models." Journal of Econometrics 68, no.1: 29-51.

Balassa, B. 1964. "The Purchasing Power Parity Doctrine A Re-appraisal." Journal of Political Economy 72, no.6: 584-96.

Barro R.J., and X. Sala-i-Martin. 1992. "Convergence." Journal of Political Economy 100, no.2:22351.

Baumol, W. 1986. "Productivity Growth, Convergence, and Welfare: What the Long-run Data Show." American Economic Review 76: 107185.

Blundell, R., and S. Bond, 1998. "Initial Conditions and Moment Restrictions in Dynamic Panel Data Models." Journal of Econometrics 87,no.1:115-43.

Bohle D., and B. Greskovits. 2012. "Capitalist Diversity on Europe's Periphery." Cornell University Press, Cornell Studies in Political Economy.

Borsi M. T., and N. Metiu. 2014. "The Evolution of Economic Convergence in the European Union." Empirical Economics

Cavenaile L., and D. Dubois. 2011. "An Empirical Analysis of Income Convergence in the European Union." Appl Econ Letters 18:17058.

Dobrinsky, R., and P. Havlik. 2014. "Economic Convergence and Structural Change: the Role of Transition and EU Accession." The Vienna Institute for International Economic Studies, Research Report 395.

Felipe, J., U. Kumar, A. Abdon, and M. Bacate. 2012. "Product Complexity and Economic Development." Structural Change and Economic Dynamics 231: 3668.

Gaulier, G., and S. Zignago. 2010. "BACI: International Trade Database at the Product-level. The 19942007 version." Working Paper 2010-23, CEPII Research Center.

Gill, I., M. Raiser, A. DallOlio, T. Packard, K. Richter, N. Sugawara, R. Veugelers, and J. Zalduendo. 2012. "Golden Growth: Restoring the lustre of European growth model." World Bank: Washington, DC.

Hausmann, R., and B. Klinger. 2007. "The Structure of the Product Space and the Evolution of Comparative Advantage." CID Working Paper, Harvard 
University, 146:1-40.

Hausmann, R., J. Hwang, and D. Rodrik. 2007. "What You Export Matters." Journal of Economic Growth 12, no.1: 125.

Hausmann, R., C. Hidalgo, S. Bustos, M. Coscia, S. Chung, J. Jimenez, et al. 2011.

"The Atlas of Economic Complexity." Puritan Press.

Hidalgo, C., B. Klinger, A.L. Barabasi, and R. Hausmann. 2007. "The Product Space Conditions the Development of Nations." Science 317: 4827.

Hidalgo, C., and R. Hausmann. 2009. "The Building Blocks of Economic Complexity." Proceedings of the National Academy of Sciences of the United States of America 106, no.26: 10570-5.

IMF 2013. "GermanCentral European Supply Chain Cluster Report." Washington DC, July.

Ingianni, A. and V. Zdarek. 2009. "Real Convergence in the New Member States: Myth or Reality?" Journal of Economic Integration 24: 294320.

Kocenda, E., A. Kutan, and T. Yigit. 2006. "Pilgrims to the Eurozone: how far, how fast?" Economic Systems 30, 31127.

Mankiw, G., D. Romer, and D. Weil. 1992. "A Contribution to the Empirics of Economic Growth." Quarterly Journal of Economics 107, 40737.

Matkowski, Z. and M. Prochniak. 2007. "Economic Convergence between the CEE-8 and the European Union." Eastern European Economics 45: 5976.

Poncet S., and F. S. De Waldemar. 2013. "Export Upgrading and Growth: The Prerequisite of Domestic Embeddedness. "World Development 51: 10418.

Roodman, D. 2006. "How to Do xtabond2: An Introduction to Difference and System GMM in Stata." Working Papers 103, Center for Global Development. Stojkov, A., and J. Zalduendo. 2011. Europe as a Convergence Engine: Heterogeneity and Investment Opportunities in Emerging Europe. Policy Research Working Paper 5837, World Bank, Washington DC. 